\title{
DA JUSTIÇA E DO SUJEITO DE JUSTIÇA NO DEBATE ENTRE NANCY FRASER E AXEL HONNETH
}

\author{
Vinícius Ferreira Baptista ${ }^{1}$
}

\section{Resumo}

Este ensaio tem por objetivo discutir estudos de Nancy Fraser e Axel Honneth na perspectiva dialógica de sujeito de Justiça, enquadramento e sujeito moral. Para tanto, analisamos o trabalho em que os autores se situam frente a frente, assim como cotejamos obras paralelas de ambos, ao mesmo tempo em que construímos um fio teórico observando suas obras individuais em que a noção de sujeito e Justiça se apresentam. A questão que os coloca em confronto não é a relação reconhecimento versus redistribuição, mas a construção de onde se parte a análise: (i) se da perspectiva macro ou microssocial, (ii) se de relações estruturais mais amplas ou de processos de subjetivação construídas na ética, (iii) se do princípio basilar de uma vida boa inicial ou construída paulatinamente. São questões que, obviamente, postas das formas argumentativas como os autores subscrevem, parecem ser opostas, porém, o que vemos é, de fato, um avanço no debate, e não uma estagnação pela mera discordância entre autores. Nancy Fraser e Axel Honneth contribuem, nesse ponto, para o desenvolvimento da Teoria Crítica em seu ponto mais fundamental: desenvolver elementos que permitam a compreensão da realidade com perspectivas engajadas de mudança social.

Palavras-chave: Teoria Crítica; Nancy Fraser; Axel Honneth; Sujeito de Justiça; Justiça.

\begin{abstract}
This essay aims to discuss studies by Nancy Fraser and Axel Honneth in the dialogical perspective of the subject of Justice, framing and moral subject. For that, we analyze the work in which the authors are face to face, as well as collating parallel works by both, at the same time that we build a theoretical thread observing their individual works in which the notion of subject and Justice are presented. The issue that confronts them is not the relationship of recognition versus redistribution, but the construction from which the analysis starts: (i) whether from a macro or microsocial perspective, (ii) whether from broader structural relationships or from processes of subjectivity built on ethics, (iii) whether from the basic principle of an initial good life or built gradually. These are questions that, obviously, posed by the argumentative forms as the authors subscribe, seems opposed to each other, however, what we see is, in fact, an advance in the debate, and not a stagnation due to the mere disagreement between authors. Nancy Fraser and Axel Honneth contribute, at this point, to the development of Critical Theory at its most fundamental point: to develop elements that allow the understanding of reality with engaged perspectives of social change.
\end{abstract}

Keywords: Critical Theory; Nancy Fraser; Axel Honneth; Subject of Justice; Justice.

\section{Resumen}

Este ensayo tiene como objetivo discutir los estudios de Nancy Fraser y Axel Honneth en la perspectiva dialógica del tema de la justicia, el encuadre y el tema moral. Para eso, analizamos el trabajo en el que los autores se encuentran cara a cara, así como también recopilamos trabajos paralelos de ambos, al mismo tiempo que construimos un hilo teórico observando sus trabajos individuales en los que se presenta la noción de sujeto y Justicia. El problema que los confronta no es la relación de reconocimiento versus

\footnotetext{
${ }^{1}$ Doutor em Políticas Públicas e Formação Humana, Universidade do Estado do Rio de Janeiro (UERJ); Professor Adjunto do Departamento de Administração Pública e do Programa de Pós-graduação em Desenvolvimento Territorial e Políticas Públicas da Universidade Federal Rural do Rio de Janeiro (UFRRJ); viniciusferbap2007@hotmail.com.
} 
redistribución, sino la construcción desde la cual comienza el análisis: (i) ya sea desde la perspectiva macro o micro social, (ii) ya sea desde relaciones estructurales más amplias o desde procesos de subjetivación construidos en ética, (iii) se basa en el principio básico de una buena vida construida inicialmente o gradualmente. Estas son preguntas que, obviamente, planteadas por las formas argumentativas a medida que los autores se suscriben, parecen oponerse, sin embargo, lo que vemos es, de hecho, un avance en el debate, y no un estancamiento debido al mero desacuerdo entre los autores. Nancy Fraser y Axel Honneth contribuyen, en este punto, al desarrollo de la teoría crítica en su punto más fundamental: desarrollar elementos que permitan la comprensión de la realidad con perspectivas comprometidas de cambio social.

Palabras-clave: Teoría crítica; Nancy Fraser; Axel Honneth; Sujeto de justicia; Justicia.

\section{INTRODUÇÃO}

Desde a publicação de Uma Teoria da Justiça, de John Rawls (1971), vemos a Filosofia Política voltar-se à Justiça e ao sujeito como bases de compreensão tanto do ponto de vista moral quanto ético. No campo de Teoria Política, a influência de Rawls alcançou a perspectiva normativa de uma série de autores do ponto de vista liberal como Ronald Dworkin (1985), Susan Okin (1989); ou do lado comunitarista com Iris Marion Young, até do ponto de vista da Teoria Crítica como Nancy Fraser, Seyla Benhabib (1992), Axel Honneth (2007, 2003) e Rainer Forst (2010). Não é nosso objetivo discutir todos esses autores, apesar de cotejarmos alguns em determinado momento do presente texto, mas situar um dos debates do início dos anos 2000, que iniciaram a perspectiva da Justiça dentro da Teoria Crítica.

O presente ensaio, portanto, apresenta e discute contextos e definições apresentadas por Nancy Fraser (2017, 2016, 2013, 2009) e Axel Honneth (2007, 2003) no que se refere a questões como Justiça e sujeitos. Ainda que, especificamente, não observadas todas as obras em que os autores dialogam, os trabalhos analisados permitem certo confronto entre os estudos e apresentação de certas discussões. Metodologicamente, aplicamos a pesquisa bibliográfica cotejando textos dos autores que versavam sobre as temáticas da Justiça, Redistribuição, Reconhecimento e Sujeitos de Justiça, a partir de suas contribuições ao campo da Teoria Crítica.

Primeiramente, situamos o pensamento de Nancy Fraser, observando capítulos do livro escrito com Honneth, Redistribution or Recognition (FRASER; HONNETH, 2003). Não obstante, como a discussão se centraliza nos apontamos da autora, selecionamos outros livros seus que apresentam facetas da construção de seu argumento. Esses textos escolhidos são, em sua maioria, posteriores ao livro conjunto com Honneth (FRASER; HONNETH, 2003), sendo publicados de 2009 a 2017. Em seguida, destacamos outros dois livros de Axel Honneth, anteriores a já citada coletânea com Fraser, em que desenvolve suas críticas contidas no livro em coautoria com Fraser, publicados em 2003 e 2007. Por fim, construímos algumas das relações propostas entre os autores que não se esgotam em si mesmos. 
Não se trata, exclusivamente, da análise dos argumentos dos autores em termos cronológicos de sua exposição nos capítulos do livro Redistribution or Recognition, de autoria de Fraser e Honneth (2003). Os pontos de discussão levantados ao longo do livro que os distanciam e aproximam, serão cotejados com outros autores do campo, tendo em vista que o assunto em si é incapaz de ser esgotável dentro da própria Teoria Crítica, o que nos move a desenvolver argumentos em conjunto com outras correntes, considerando as limitações de cada uma.

Nesse sentido, vemos a questão da Justiça sair da perspectiva unicamente moral, processual ou circunscrita em bases territoriais, para uma perspectiva de alcance global, como Nancy Fraser (2009) pondera, uma "perspectiva pós-Westfaliana". A Teoria Crítica, ao abraçar a discussão da Justiça e do sujeito de Justiça, passou a considerá-los como inerentes ao processo de mudança social. Afinal, não há como situar questões como cidadania, Justiça e bem-estar em condições sociais onde pessoas são postas ao convívio diário com rebaixamentos e negligências. Destacamos que a Teoria Crítica, ao desenvolver a questão da Justiça, procura distanciar-se de elementos lineares e moralizantes, assim como se defronta na ótica de mudança social (e não na perspectiva de justiça ou cidadania "plena") que, quando confrontada na lógica do sujeito de Justiça, se observa que existe um sujeito bem definido em termos de acesso à Justiça.

$\mathrm{Na}$ perspectiva do debate entre Nancy Fraser e Axel Honneth, vemos um embate à procura de ressignificação da Teoria Crítica. Na disputa entre esses autores, no que se refere ao ideal normativo e compreensivo acerca das bases teóricas, observamos que ambos concordam em alguns elementos: a relação dialética histórica entre desigualdades, o sistema capitalista, o sofrimento e as determinações relacionadas. Contudo, os autores divergem sobre aspectos explicativos e causais dessas relações, notadamente, no que trata das bases macro ou microssociais, estruturais ou não.

Fraser pondera que não há uma perspectiva que possa ser "micro" no âmbito do reconhecimento e das disputas individuais ou grupais unicamente. Há de se considerar elementos socioeconômicos e político-institucionais relativos à redistribuição. Já Axel Honneth segue a linha de raciocínio hegeliana, pautando-se no reconhecimento como categoria que não apenas incorpora, como entende Fraser, mas que organiza todo o sistema social, da redistribuição ao casamento, dos contratos aos indivíduos.

Vemos que os dois autores divergem em pontos nodais, entretanto, se aproximam intensamente. A questão que os coloca em confronto não é a relação reconhecimento versus redistribuição, mas a construção de onde se parte a análise: se da perspectiva macro ou microssocial, se de relações estruturais mais amplas ou de processos de subjetivação construídas na ética, se do princípio basilar de uma vida boa inicial ou se construída paulatinamente. O ponto 
inconciliável entre os dois está na questão da "boa" vida e da concepção de "bem", se acontecem em termos estruturais ou microssociais, e se são necessários previamente para se pensar a Justiça.

\section{DA JUSTIÇA E DO SUJEITO EM NANCY FRASER}

Nancy Fraser tem argumentação histórica bem delimitada no campo da Justiça e suas relações políticas no campo dos estudos de gênero, sobretudo em termos de seus principais debatedores (BUTLER, 1999; BENHABIB, 1992; CORNELL, 1998; OKIN, 1989; PHILLIPS, 2011; RHODE, 1991; YOUNG, 1997, 2011). Durante o período dos anos 1990, Fraser debateu, especificamente, a respeito dos elementos da Teoria Crítica no âmbito do reconhecimento e das pautas feministas. Ao fim dessa década e até quase metade dos anos 2000, Fraser constrói seu sistema bidimensional, duramente criticado por Iris Marion Young $(1997,2011)$ pelo fato da autora sublimar as questões políticas, reduzir as lutas feministas ao alcance preponderante do desenvolvimento econômico e, em sentido mais controverso, de reduzir as pautas feministas da chamada terceira onda a questões identitárias que possam ser usadas, metodologicamente, para legitimar grupos sociais conflitivos. Contudo, ao longo da primeira década dos anos 2000, Fraser rompe com essa noção acrescentando uma terceira dimensão, agora um sistema triparte melhor estruturado, ao incorporar a representação. Apesar disso, a construção do presente trabalho se norteará pelo debate dos estudos de Fraser com Honneth e indicaremos, quando pertinente, em quais pontos Fraser já não se situa no mesmo aspecto conceitual.

Assim como Samuel Fleischacker (2006), Fraser (2009, 1989; FRASER, HONNETH, 2003) pondera que as reivindicações redistributivas igualitárias são o paradigma maior da teorização sobre a Justiça social no que se configura o período pós segunda onda do feminismo. Não obstante, situa o embate entre reconhecimento e redistribuição, muitas vezes dissociadas e vistas como antagônicas (FRASER; HONNETH, 2003, p. 19) - paralelamente, destaca que a consideração de uma sem o sentido dialético seria inócua, portanto, a questão da Justiça social comportaria um propósito bidimensional.

Fleischacker (2006) pondera que, dentro da perspectiva redistributiva, o grande perigo está em se considerar a dimensão da renda como fator motriz do processo de desenvolvimento humano - em certa medida atrelada à dimensão do capital humano. Consequentemente, as questões podem ser reduzidas à mera transferência de renda ou de políticas que venham permitir desenvolvimento de ações vinculadas à renda, como o trabalho. Dentro da perspectiva feminista, Angela Davis (1983) considera que podemos ter uma sumária exclusão de sujeitos vistos de forma essencialista, sendo "incluídos" em políticas de renda e trabalho que não consideram as diferenças dentro das diferenças. 
Essa é uma das "sombras da Justiça" pautadas na lógica redistributiva que encontramos nos argumentos de Katrina Forrester (2019), quando analisa as influências de Rawls nas políticas de Justiça socioeconômica. As políticas redistributivas são, em grande parte, consideradas como nível macro e, não necessariamente, são capazes de observar as diferenças, logo, tratam de atomizar os sujeitos sociais e suas condições enfrentadas. A lógica aqui é a de maior ganho social, o que nos faz questionar: Será uma parte utilitarista justamente o que Rawls enfrentava? Assim, esse paradigma redistributivo, na lógica de Fraser, é incapaz de prover mudança social, quando desconsidera a Justiça dos sujeitos de Justiça.

Fraser, portanto, situa seu debate com Honneth na redistribuição e no reconhecimento como referências políticas, ou seja, como paradigmas populares da Justiça, datado e contextualizados historicamente quanto às demandas, atores e processos, e atrelados às disputas argumentativas entre si. Nessa disputa temos a política de classe (para redistribuição) e a política de identidade (para reconhecimento). Na má interpretação desses paradigmas da Justiça, ocorre a falsa antítese, reificando-se como uma única perspectiva a ser solapada em todas as reivindicações e grupos (FRASER; HONNETH, 2003).

A má interpretação é a noção que cria a falsa antítese entre redistribuição e reconhecimento, tal como soma zero, em que a escolha de uma implica exclusão de outra, assim, uma se torna mais importante do que a outra. Sobretudo do ponto de vista do Estado e de seus agentes coloca escolhas públicas sob este viés antagônico de uma posição acima da outra. Nesse ponto, Fraser pondera que, assim, um paradigma popular de Justiça se associa à dimensão pública e política de convencimento e mobilização social dentro do viés de mudança, como uma demanda e chamamento frente à sociedade em termos de incitação à discussão e também de influência frente ao Estado (FRASER, 2013, 2009). Esse é um ponto nodal que distancia a abordagem da Justiça pelo viés da Teoria Crítica.

A construção da autora se dá na perspectiva de combater propostas que não observem o sentido de uma construção de sujeitos de igual valor moral dentro de contextos políticos que ressaltem a noção de sujeitos de Justiça, onde o enquadramento construído perpassa elementos morais e se distanciam de fundamentos éticos em um primeiro momento. Não obstante, atinge elementos universais em certa medida ao desvincular a Justiça do elemento territorial, ou como a autora destaca, do paradigma Westfaliano. Ademais, convém situar que esse processo teórico se dá, especialmente, ao longo dos trabalhos de Fraser pós 2006 e são consolidados em sua obra Scales of Justice de 2009.

$\mathrm{Na}$ questão da má interpretação, a qual a autora passa rapidamente, situamos concordância em três dos quatro fundamentos apresentados: 1) que as origens dos paradigmas populares 
apresentam múltiplas concepções que originam a injustiça; 2) que as soluções propostas pelos paradigmas também são derivantes múltiplas; e 3) a variada concepção do atingido coletivo da injustiça (FRASER; HONNETH, 2003).

Contudo, o quarto argumento - o de que os paradigmas populares assumem ideias distintas sobre as diferenças de grupo - contém um elemento interpretado de modo inconsistente por Fraser a partir do trabalho de Young (1990), situando-a dentre aqueles que acham a transformação cultural como objetivo privilegiado das políticas de reconhecimento. Young (1990, 1997, 2011) situa os elementos de opressão que são enraizados na estrutura social e cultural de uma sociedade e que, no objetivo de desestruturar estes sistemas opressivos, a base cultural é o elemento que não pode ser desconsiderado como parte do movimento de mudança, por cultura e estrutura social serem dinamicamente associados na dominação e opressão. Considerar a base cultural como parte intrínseca à desestruturação da opressão é diferente de colocá-la como objeto privilegiado.

Por outro lado, Fraser (FRASER; HONNETH, 2003) interpreta corretamente um ponto enfatizado por Young (1990), o de que políticas de reconhecimento que distanciem ou desconsiderem as diferenças de grupo tendem a reforçar a injustiça. Young $(1997,2011)$ destaca que a Justiça ao tomar sujeitos como universais, constrói um contexto de desigualdade, hierarquias e dominações, como se existisse a fácil identificação de quem é dominado e quem domina. A autora insiste que dentro de grupos existem diferenças e que esse contexto não está imune na reprodução da estrutura de dominação sob outras manifestações. Young (1990, 1997, 2011) destaca, por exemplo, que considerar as mulheres como um grupo universal e coeso, é desconsiderar que dentre as mulheres, existem mais diferenças estruturais e desigualdades.

Podemos seguir essa questão das opressões, para situar que Fraser $(2013,2009)$ destaca o movimento político-institucional na abstração das opressões que, notadamente, acaba por diluí-las, como se existissem, pela diferenciação social e pelo sistema capitalista, alguma forma de "escolha" ou de alcance diferenciado sobre quais formas de opressão, determinado grupo ou indivíduo pode ser atingido. Tal perspectiva já foi demonstrada anteriormente como falsa por Davis (1983) ao construir a perspectiva teórica do sistema opressivo da escravidão americana tendo em vista as mulheres negras nos EUA nos séculos XIX e XX. Assim como Audre Lorde (2007), ao argumentar que o sistema opressivo de mulheres pode incorporar elementos de classe, raça, sexualidade, território, cultura, dentre outros fenômenos que constroem a estrutura de um sistema opressivo. Também a própria Iris Young (1990) destaca isso em seu trabalho Five Faces of Oppression. Não obstante, Michele Alexander (2011), ao analisar o sistema prisional dos Estados Unidos, observa como o governo em vários momentos históricos alia condições 
econômicas, sociais, políticas, institucionais e o racismo estrutural, para construir bases constitucionais que rebaixam cidadãos negros, em sistemas legitimados associados à ordem econômica norte-americana.

A abstração das opressões, situada por Fraser, se dá tanto nas políticas de reconhecimento quanto nas de redistribuição, a depender do agente, do receptor das políticas, dos mecanismos aplicados e dos objetivos pensados. Ela organiza a perspectiva ampla, mantém a estrutura opressiva e reduz o potencial de desenvolvimento destas políticas. Há de se destacar que Benhabib (1992) já situava que esses sistemas produzem e reproduzem outros sistemas que apagam diferenças, idealizam o âmbito privado e despublicizam o âmbito público. Butler (1999) segue o mesmo raciocínio quando situa a questão dos papeis de gênero dentro da estrutura social e os embates sociais na estrutura.

Assim, em sua defesa sobre considerar, paralelamente, as políticas de redistribuição e reconhecimento, e estruturar uma concepção de sujeito de Justiça, Fraser argumentará a partir de três aspectos. O primeiro deles é afastar das políticas de reconhecimento a perspectiva da Justiça como realização pessoal, alocando uma base do direito, onde o não-reconhecimento implica a não-paridade de igual valor moral e de status como interlocutores plenos. A noção de subordinação aqui seria uma violação de Justiça - aproximando-se do sentido político em Young (1990). Afastar o reconhecimento da realização pessoal é, além de um ataque direto à Axel Honneth, uma construção no âmbito da Justiça política, onde a Justiça é uma questão de obrigação social evidenciando a reciprocidade (HÖFFE, 2006). Colocar a realização pessoal em dimensão de Justiça é situar uma perspectiva de mérito que dissocia este da conjuntura social e de como os esforços se relacionam dentro de uma ordem capitalista pós-westfaliana. Ao mesmo tempo, criaria um contexto individualista do reconhecimento, incapaz de agregar grupos e relações inter e intra grupos. Ao mesmo tempo, é um ataque à toda concepção dos direitos liberais dentro da ordem do indivíduo em "relações" unilaterais, cuja ordem da propriedade orienta conceito e prática da Justiça.

O segundo aspecto de Fraser é situar seu modelo de status para valor moral que abarca o pluralismo de valores e incide nos grupos suas próprias formas situacionais de boa vida em termos de Justiça. A autora também destaca a paridade de participação como elemento de justificação e compreensão do reconhecimento como normativamente vinculantes, trazendo noção pública e não de realização pessoal, o que permite que reconhecimento e redistribuição não se subsumam uma à outra (FRASER; HONNETH, 2003, p. 30-37). Isso também afasta as noções individualizantes das concepções liberais de Justiça, especificamente associadas ao feminismo liberal ou que tenham incrustadas em si noções de direitos individuais como 
primordiais (FRASER, 2009) e que venham a afastar o elemento político-institucional e social da Justiça política (HÖFFE, 2006). Há de se considerar que esse é um dos pontos nodais de crítica de Axel Honneth, Rainer Forst e Seyla Benhabib à Fraser e de Fraser a esses autores - que afastam a concepção inicial de vida boa como fundamental ao processo de Justiça e também a ideia da disputa do direito a ter direitos.

O terceiro aspecto está na paridade de participação, de colocar como uma gramática linguística para debate público e argumentação, evitando enfoques monológicos e reducionistas. Em certa medida, Fraser (FRASER; HONNETH, 2003, p. 45-52) se refere à Habermas (2014) no âmbito da construção de seu modelo da mudança da estrutura social e da função política da esfera pública que desconsidera a questão das mulheres, quando não as reduz à noção europeia do sujeito feminino, e que não reflete a participação política das mulheres. Em outro ponto, a autora se refere à Rawls (1971) acerca de sua dificuldade unilateral em construir um modelo de processos públicos de deliberação democrática pontuados em sujeitos representativos que desconsideram elementos estruturais historicamente situados.

Nesses três aspectos, Fraser situa seu modelo bidimensional (ou dualismo perspectivo, como denomina) como aquele que incorpora o sentido histórico das mudanças da estrutura social e da cultura política (FRASER; HONNETH, 2003, p. 53) e da diferenciação entre classe e status e suas interações causais (FRASER; HONNETH, 2003, p. 51), observando tendências conflitivas e estruturantes no âmbito da má distribuição e não-reconhecimento como fundamentais de serem combatidos. Para a autora, não há como se criar medidas paliativas e não-reformistas, quando, na verdade, a questão é destruir o sistema pela sua estrutura em si.

O centro de atenção de Fraser é o discursivo, notadamente no âmbito pluralista para a possibilidade de transformação radical da sociedade. Para ela, a transformação não passa unicamente pela dimensão cultural, como para Honneth, que reduz toda a subordinação social ao mal reconhecimento produzido pela hierarquização desta dimensão. Para Fraser, a subordinação é uma questão política de Justiça mediada pelo status e sua expressão institucional (FRASER; HONNETH, 2003, p. 164). O pluralismo em Fraser é essencial para o desenvolvimento daquilo que viria a ser sua dimensão tripartite, contudo, não devemos considerá-lo em sua versão atenuada na lógica liberal que vemos, por exemplo em Dahl (1989), onde o pluralismo assume uma vertente de total integração na lógica democrática e sem qualquer capacidade de contestação, em que passa incólume às disputas morais e fundamentalistas. Fraser deixa claro em obras posteriores (FRASER, 2009) que a dimensão plural não necessariamente significa que ela seja sem disputas, mas que o elemento de Justiça significa que ninguém seja rebaixado no contexto 
plural de valores. Essa é a diferença da compreensão, uma vez que o ambiente plural não necessariamente significa um ambiente livre de hierarquias culturais.

Para consolidar, destacamos que, em trabalhos posteriores ao debate com Honneth, Fraser (2009) constrói o argumento de que qualquer proposta de Justiça que seja válida normativamente deve considerar três elementos: a redistribuição, o reconhecimento e a representação com cada qual assumindo um plano específico. A redistribuição (a dimensão econômica), compreende o "que" (What), ou seja, o objeto disputado da Justiça. O reconhecimento (a dimensão cultural) compreende o "quem", as pessoas que serão afetadas pela configuração esquemática da Justiça (Who). A representação (a dimensão política) situa o "Como" (How) as construções institucionais criadas para tal.

Seu conceito de "paridade de participação" está ligado ao de Justiça, ou seja, que só existe a segunda quando a primeira é a base que a sustenta conceitual e procedimentalmente, por "desmantelar os obstáculos institucionalizados que impedem algumas pessoas de participarem em paridade uns com os outros, como parceiros completos de interação" (FRASER, 2009, p. 60). Isso significa que a avaliação da democracia e de normas envolve a compreensão de que somente seriam legítimas se se atentassem em processos justos e abertos de deliberação em que todos participem como pares.

Para Fraser (2013, 2009), falar em Justiça é considerar a forma como os indivíduos estão posicionados uns em relação aos outros nas diferentes dimensões da vida, desde à política, à economia, passando pelo sistema jurídico e a ordem social. A paridade de participação é um instrumento normativo que considera as diferentes concepções morais de vida boa a partir de um critério: a paridade. Se as pessoas participam em iguais condições e são sujeitos de Justiça em igual equivalência moral, podemos falar em Justiça. Nesse ponto, a concepção de vida boa em Fraser se organiza pela paridade. E é aqui que se constrói sua noção de "sujeitos de Justiça". Fraser propõe uma Justiça reflexiva, que incorpore demandas de desiguais e correlacione as meta-divergências atreladas neste processo. Não vemos isso no debate com Honneth, contudo, situamos como importante, por demonstrar que a autora vem desenvolvendo sua argumentação, ao rever alguns de seus posicionamentos em obras posteriores (FRASER, 2017, 2016, 2013).

\section{DA JUSTIÇA E DO SUJEITO EM AXEL HONNETH}

O conceito de Reconhecimento, em Axel Honneth, não é explorado em sua obra em coautoria com Nancy Fraser (FRASER; HONNETH, 2003), uma vez que que o debate é proposto a partir de Fraser com réplicas de Honneth. Assim, só podemos compreender o conceito do autor resgatando suas obras anteriores (HONNEHT, 2007, 2003) para, em seguida, 
examinar suas réplicas à autora. Seu conceito de Reconhecimento é pautado pela lógica hegeliana de luta social, onde se assume uma disputa pela gramática moral dos conflitos sociais, em dimensão de intersubjetividade.

Para Honneth $(2007,2003)$, o reconhecimento envolve os modos de intersubjetividade que nas relações sociais se estabelecem no processo em que sujeitos se reconhecem reciprocamente como seres e sujeitos, seja como seres amantes, ou portadores de pretensões jurídicas ou de pertencimento de si e na ordem social. Para o autor, a reprodução da vida social se efetua em um reconhecimento recíproco, pois os sujeitos só podem chegar “a uma autorrelação prática quando aprendem a se conceber, da perspectiva normativa de seus parceiros de interação, como seus destinatários sociais" (HONNETH, 2007, p. 155). Aqui, tanto Fraser quanto Honneth destacam o Reconhecimento a partir da reciprocidade das interações sociais.

Essas formas de reconhecimento são disputadas em gramáticas morais, ou seja, formas de linguagem, apreensão, codificação e interpretação de elementos morais que organizam atos de fala, comportamento e expectativas de indivíduos como sujeitos sociais e morais (HONNETH, 2007). Não obstante, essas lutas moralmente motivadas são tentativas de estabelecimento de formas ampliadas institucionais e culturais de reconhecimento recíproco que geram as transformações normativas das sociedades (HONNETH, 2003). Para o autor, o reconhecimento é uma esfera moral e normativa pautada por três dimensões que formam o processo de socialização: amor (relações afetivas primárias), direito (relações de igualdade jurídica) e estima (relações sociais amplas).

Esse processo de socialização é concreto e se dá nas relações materiais e imateriais das relações sociais, em que as formas de reconhecimento dependem diretamente das experiências das pessoas. Consequentemente, são erguidas as dimensões de status sociais dispostos nessas formas de reconhecimento que são reivindicadas pelos sujeitos. Aqui, Honneth argumenta a construção histórica de Marshall (1967) de como reconhecimentos intersubjetivos transformam seus status em condições jurídicas que orientam normativamente a sociedade e como as transformações sociais pelas reivindicações de reconhecimento reorientam as relações sociais e os próprios status.

Honneth (2007) se refere ao processo dos direitos civis, políticos e sociais e em como estes foram frutos de lutas sociais por interpretações mais abrangentes de direitos na lógica universal, nos quais são colocados os diferentes indivíduos como de igual valor moral, ou seja, indivíduos que se reconhecem intersubjetivamente como iguais. É claro que esse reconhecimento se dá em lutas, tendo em vista que direitos de grupos específicos se orientam pelo reconhecimento apenas destes vinculados e não dos que estariam "de fora”, ou melhor, um reconhecimento rebaixado. 
O reconhecimento, portanto, se liga à dimensão ética e moral, de pertencimento, relevância e individualidade dentro da ordem social de indivíduos que devem ser respeitados por sua existência e ser considerados parte da sociedade. Honneth (2007, 2003) segue o mesmo enquadramento de Fraser no que se refere à "quebra" do reconhecimento com a noção de mal reconhecimento, que ela denomina como má interpretação.

A estrutura das relações sociais de reconhecimento envolve três modos de reconhecimento: dedicação emotiva (amor), respeito cognitivo (direito) e estima social (estima), e suas formas de desrespeito são, respectivamente, maus tratos, exclusão e degradação. Os componentes ameaçados são, igualmente, a integridade física, a integralidade social e a dignidade. No caso das quebras das relações pelo desrespeito, a integridade do indivíduo e sua percepção de si são indeterminadas, construindo seres sociais de relações de desigualdade. Essa quebra causa, o que o autor denomina por sofrimento por indeterminação, onde não há reconhecimento intersubjetivo e capacidade de desenvolvimento autônomo entre indivíduos iguais (HONNETH, 2007, 2003).

Nesse ponto, Honneth (FRASER; HONNETH, 2003) entende que as dimensões de redistribuição são derivações do reconhecimento, tendo em vista que, ao balizar indivíduos que são respeitados e os que não são respeitados nas relações afetivas, jurídicas e sociais, as hierarquizações institucionalizadas reverberam nas demais esferas da vida, a exemplo da econômica e das redistribuições de renda e oportunidades. As relações primárias iniciam o momento da intersubjetividade e quando ocorre uma quebra no autorrespeito, as demais formas de reconhecimento são prejudicadas (HONNETH, 2007, 2003). Por isso que não se é capaz de se ater à uma boa vida em perspectiva inicial, já que as relações sociais construirão este processo, que poderá, assim, ser desigual e apontar hierarquias sociais.

A primeira dimensão do reconhecimento em Honneth está nas relações íntimas - o amor (FRASER; HONNETH, 2003; HONNETH, 2007, 2003). Quando respeitado, ele implica a autoconfiança, mas seu desrespeito produz violência. Como exemplo, em uma sociedade machista e patriarcal, a construção sociopolítica se dá na primazia masculina; ou seja, a atuação violenta institucionalizada dos maridos sobre as mulheres seria uma questão de respeito e o questionamento da mulher seria uma indicação de não respeito e violência contra a autoconfiança do homem. A mesma relação poderia ser exemplificada na perspectiva do racismo.

Fraser destaca que isso é uma posição dúbia, em que o amor, como parte da dimensão da Justiça nas relações sociais, pode situar relações de hierarquia e subordinação "atenuadas" pelo afeto (FRASER; HONNETH, 2003). Honneth se defenderá dizendo que Fraser interpretou erroneamente e menos do que elevando seus argumentos, ainda assim, indicará que se perpassa 
uma eticidade nas relações, um fundamento ético que impediria determinadas construções sociais hierarquizantes serem atreladas a esses processos de reconhecimento das três formas de sua manifestação. Vale lembrar que esse é o mesmo argumento quanto à questão de Fraser sobre a possibilidade de o reconhecimento levantar elemento normativo justificatório a qualquer reivindicação de reconhecimento.

Já Fraser destaca que tanto redistribuição quanto reconhecimento possuem suas características específicas quanto as de tipo relacional entre uma dimensão e a outra. Para Honneth, a estrutura social perpassa delimitações de reconhecimento em bases íntimas, jurídicas e sociais, cada qual com sua complexidade, formando os estágios de desenvolvimento do ser humano e uma falha em algum momento do trajeto implicaria algum grau de sofrimento. Diferentemente como situa Fraser, Honneth não construiria seu argumento de forma unilateral, pois, a todo instante, o reconhecimento é sistema social e a integração social não permitiria este processo. Por último, é um fato que Honneth não aproveita o potencial da crítica de Fraser sobre a abstração do reconhecimento que abrangeria reivindicações ilegítimas - o autor traz o elemento ético e a eticidade à baila, mas sua construção, focada mais na apresentação de respostas ao sistema bidimensional do que na crítica da autora, enfraquece este ponto da argumentação do autor.

Em Honneth, vemos dois elementos críticos que o distanciam de Fraser: 1) na compreensão da ordem social capitalista, é necessário incluir as três esferas e os valores culturais atrelados na constituição institucional da esfera econômica; 2) os conflitos e as lutas das formações sociais capitalistas têm relação com os princípios de reconhecimento mútuo (FRASER; HONNETH, 2003, p. 125). Nesse ponto, há mais um distanciamento, pois Honneth admite em seu esquema a fluidez dos indivíduos nas relações sociais, sem a preocupação com um sistema que balize o processo de tratamento de Justiça, como tenta Fraser em sua paridade de participação.

Aqui, o debate entre Honneth e Fraser lembra, em parte, a aplicação lexical de Rawls (1971, 1996) dos seus princípios de Justiça: 1) liberdades iguais para todos e 2) desigualdades sociais que melhorem a vida de todos na lógica do princípio da diferença. Em que o segundo princípio, mais fluido, observa as relações sociais em andamento e procura atuar aplicando a Justiça, a fim de enquadrar o alcance do primeiro. Em Honneth, vemos a sofisticação de considerar a mudança social nos contextos de Justiça como o próprio autor se defende dos ataques de Fraser apontando que sua teoria se constrói pelos contextos e não os incorpora "depois". Em Fraser, vemos o refinamento argumentativo na base moral de um sujeito de Justiça que não pode ser rebaixado em momento algum em detrimento de um fraco e instável pluralismo. 
Para Honneth, toda integração social depende de formas de reconhecimento e o não-reconhecimento é o motor das trocas sociais. Aqui, tem-se um "núcleo de expectativas de reconhecimento que todos os sujeitos depositam na interação social" (FRASER; HONNETH, 2003, p. 184). Honneth percebe os riscos desta generalização e coloca como desafio a descoberta da estrutura dos sentimentos relativos ao reconhecimento. É, nessa estrutura, que entra o que autor chama de construção "débill" de uma noção de bem ao argumentar que onde a eticidade entra concomitantemente à construção do desenvolvimento do sujeito na relação do reconhecimento há um processo conjunto e não um modelo dado e pronto a partir da comparação entre as diversas formas relacionais de indivíduos. Por isso, não há concepção de boa vida nem bem de início. Diferentemente de Fraser, que coloca à frente uma concepção estruturada de bem para o seu modelo bidimensional da paridade de participação, ao delimitar os sujeitos de justiça em termos de suas fronteiras, construindo um processo onde elementos morais dão o norte, de forma substantiva e comparativa, para intra-sociedades, em termos de participação social (FRASER; HONNETH, 2003).

Em Honneth, por fim, vemos o elemento moral com caráter mais incisivo e forte do que em Fraser, que procura afastá-lo e trazê-lo conforme o modelo bidimensional vai sendo aplicado. Para Honneth, a injustiça é falha no reconhecimento, que vai abrangendo outras esferas da vida, sendo que, se de início seja falho, isso não significa que se estacione, pelo contrário, as relações incorporam aquela falha de indeterminação e se prosseguem as relações sociais falhas. Isso é importante, porque pode se ter a compreensão de que Honneth seja linear na figura do reconhecimento, como se seus três "estágios" (amor, jurídico e social) fossem acúmulos.

A crítica da Teoria honnethiana está em situar o reconhecimento como perspectiva moral, mas também normativa que não coloque uma concepção de vida "boa" já que as fragilidades do reconhecimento e sua base construtiva se dão nas próprias relações pessoais entre indivíduos. Portanto, não teríamos como colocar medidas paritárias de participação entre indivíduos, como faz Fraser. Os sujeitos de Justiça de Honneth atuam como atores morais, que reivindicam bases normativas e possuem vulnerabilidades. Há de se considerar elementos individuais e comunitários, a fim de ser evitar sofrimentos.

\section{A CONTRIBUIÇÃO DO DEBATE FRASER-HONNETH}

$\mathrm{Na}$ justificação das reivindicações, Fraser pontua que a noção de reconhecimento de Honneth $(2003$, 2007) baseia-se pelo autorrespeito, autoestima e autoconfiança que envolve o reconhecimento pleno de suas bases morais. A autora situa que todas as reivindicações de autoestima estarão justificáveis, sejam elas provenientes dos negros e mulheres, ou de neonazistas 
e da Ku Klux Klan. Em um primeiro momento, a autora, ao debater com Honneth, abstrai o elemento ético das reivindicações e o sentido argumentativo que envolve a esfera pública e coloca no mesmo esquema reinvindicações completamente diferentes - as duas primeiras pela inclusão no sistema e as duas últimas pela exclusão.

Essa abstração tem um duplo jogo. Por um lado, coloca as duas formas de reivindicação no mesmo plano, em justificações distintas por uma ótica especificamente discursiva do respeito. Aqui, o ataque à Fraser é justificável, tal como o fazem Benhabib (1992) e Young (2011). Por outro, deixa claro a possibilidade de que sejam manipuladas, discursivamente, a questão da tolerância aos grupos via reconhecimento, pela permanência das suas reivindicações no sistema político ainda que as mesmas sejam pela exclusão de grupos. E aqui, Honneth (FRASER; HONNETH, 2003) argumenta contra Fraser, desconsiderando os perigos levantados pela autora, sobretudo à possibilidade de incorporação do autorrespeito por grupos de extermínio.

Nesse ponto, vemos uma das críticas mais ácidas de Fraser, quanto ao "monismo cultural" de Honneth (FRASER; HONNETH, 2003, p. 150), especificamente quanto ao reconhecimento como equalizador de todos os defeitos normativos da sociedade, criando uma "psicologia moral do sofrimento pré-político" (FRASER; HONNETH, 2003, p. 152), colocando em dúvida a negação do reconhecimento como única motivação do descontentamento. Para Fraser, a negação não é o núcleo normativo, mas um tipo de injustiça dentre outros (FRASER; HONNETH, 2003, p. 153). Vemos o reconhecimento como a única categoria moral de experiência autêntica de Justiça, impedindo a dialética.

Esse ponto é significativo porque sofrimento na base da psicologia moral em ótica monista cultural não leva em conta como sentimentos e sofrimentos podem ser manipulados para causar distanciamento na capacidade associativa, pois os paradigmas populares incitam a compreensão e mobilização social (FRASER, 2017, 2013, 2009). Ao mesmo tempo, essa construção, a princípio, pode assumir caráter universalista e essencialista de modos subjetivos de ser, viver e compreender a realidade a partir de papeis e comportamentos fixos, em que esta manipulação restringe a capacidade de se considerar o sofrimento como tal, mas uma realidade "normal" à que o indivíduo se ajusta (BUTLER, 1999).

A base psicológico-moral anteciparia as questões abrindo mão da explicação moral e da justificação normativa. Por isso não haveria, de acordo com Fraser (FRASER; HONNETH, 2003), uma noção de vida boa em Honneth. Em certa medida, não há, até porque seguindo o raciocínio do autor (HONNETH, 2007, 2003), onde as fragilidades do reconhecimento e sua base construtiva se dão nas próprias relações, não há como antever essa concepção de forma cristalina, ainda que a questão da má interpretação e sofrimento venham a emergir. Há uma 
concepção de fato, mas não necessariamente vinculante normativamente em um primeiro momento.

Ter uma concepção prévia de vida boa é assumir a perspectiva de Fraser (2017, 2013, 2009) de que se necessita de parâmetros normativos que possam considerar a Justiça em forma equitativa. Por isso, a autora realiza o esforço de sua base teórica bidimensional a partir da paridade de participação, onde se tem como parâmetro comparativo elementos morais, a exemplo da vida boa, considerando o não rebaixamento das pessoas por condições morais, nem sua exclusão por doutrinas morais abrangentes, como diria Rawls (1999). Fraser, portanto, cria uma barreira para impedir a má interpretação de paradigmas da Justiça a fim de evitá-los.

Por outro lado, seguindo o raciocínio de Honneth (2007, 2003), delimitar uma composição de vida boa é já antecipar aspectos mínimos entre indivíduos sem ao menos que os mesmos tenham a possibilidade de empreender relações sociais, onde ajustariam, pela autoconfiança, autorrespeito e autoestima, sua concepção relacional de boa vida. Ele entende que não se pode ter má interpretação quando os indivíduos são postos em sua capacidade relacional.

Uma questão que Fraser levanta é: até que ponto subsumir estruturas econômicas e políticas ao afeto (reconhecimento pelo amor) mascaram as relações? A autora (FRASER; HONNETH, 2003) não desenvolve seu argumento, contudo, sugere que circunscrever relações sociais mais amplas e estruturais em relações sociais de indivíduos é afastar composições de uma estrutura social como um todo, em sentido de que o afeto permearia as dimensões de opressão econômica, política e até jurídica.

Em todo o debate entre os autores, Axel Honneth acusa Fraser de dar primazia à redistribuição em detrimento ao reconhecimento. Honneth (FRASER; HONNETH, 2003) situa que há uma relação de desequilíbrio entre reconhecimento e redistribuição especificamente no ponto filosófico, portanto, entende a necessidade de investigação das linguagens teóricas melhor adaptadas às justificações normativas nas reivindicações políticas, onde o reconhecimento situaria os termos que, consequentemente, derivariam a redistribuição. Ele destaca que Fraser homogeiniza os movimentos sociais, sobretudo, os midiáticos, tornando-os "identitários", o que afasta uma série de exclusões e opressões e os "anacroniza" situando-os como "dados" (FRASER; HONNETH, 2003, p. 99-100). Os sofrimentos sociais são, assim, padronizados, o que reproduz exclusões políticas. Em certa medida, é possível verificar um etnocentrismo na argumentação de Fraser, notadamente na construção dos movimentos sociais, onde a autora essencializa (BUTLER, 1999) a figura da mulher, planificando as diferentes formas de opressão (YOUNG, 1997, 2011) que desconsidera elementos raciais (DAVIS, 1983) e sexuais (LORDE, 2007). De fato, não é a primeira vez que Fraser é acusada neste sentido e, verificando os dois 
capítulos escritos para a obra conjunta com Honneth, apenas em uma única nota de rodapé a autora destaca a obra de Angela Davis (1983), quando aborda a questão do racismo.

Destacamos também que Fraser situa toda a sua obra, a partir dos anos 2000, na lógica dos Estados Unidos e centraliza suas críticas da Justiça com base neste país (FRASER, 2013, 2016, 2017). Notadamente, suas análises sobre o capitalismo, o cuidado, o trabalho não remunerado e as demandas feministas, levam em consideração os Estados Unidos - e isso pode ser considerado um problema em sua crítica aos paradigmas populares. Especificamente, em sua análise sobre o cuidado, Fraser (FRASER; HONNETH, 2003; FRASER, 2009) continua aplicando seu modelo, agora tripartite e não dualista, no âmbito da mulher norte-americana sem muitas vezes considerar os marcadores sociais. E quando os considera, não os incorpora criticamente.

Convém sobressair que Honneth (2007) já destacava que os anacronismos de grupos e suas referentes reivindicações criam uma plataforma que associa reivindicações de grupos à direitos individuais aportando uma construção racional instrumental que afasta qualquer possibilidade discursiva sobre diferenças entre e intra grupos. Ademais, o próprio autor argumenta que Fraser atribui essa racionalidade instrumental a grupos que acabam por esvaziar o sujeito como atores morais, retirando reivindicações normativas e suas vulnerabilidades, criando interesses particulares unívocos e posteriormente, universais. Para Honneth, o sofrimento possui um núcleo normativo e esta instrumentalização incidirá sobre a indeterminação e decorrente mal reconhecimento (FRASER; HONNETH, 2003, p. 103-106).

Nessa perspectiva, Honneth aponta, na política de identidade, dois mecanismos reivindicatórios: os individualistas e os comuns (FRASER; HONNETH, 2003, p. 129). Os individualistas impedem reconhecimento enquanto membros de grupos. Os comuns impedem o tratamento jurídico igualitário em relação a outros grupos. Trata-se de coesão da comunidade daí a disputa por recursos e reconhecimento (FRASER; HONNETH, 2003, p. 130). O anacronismo e reificação de grupos sociais acaba por impedir a coesão da comunidade, por não considerar nem elementos individuais nem comunitárias, gerando sofrimentos.

O sofrimento é uma injustiça e essas são experiências de negação do reconhecimento falhas de respeito (FRASER; HONNETH, 2003, p. 112). Essas experiências se associam não ao objeto, mas à forma de reconhecimento. Assim, temos três esferas: amor, lei e estima (FRASER; HONNETH, 2003, p. 109-113), com suas formas sociais relacionais e princípios. Suas formas de reconhecimento distintas, em três tipos de relações: íntimas, jurídicas e sociais. Em Fraser, vemos que a injustiça corresponde a não possibilidade de paridade de participação em condições de igual valor moral entre sujeitos de Justiça e estas experiências se associam não ao reconhecimento, mas ao objeto e como este se dá em relação ao sistema capitalista. 
Nesse ponto, a crítica de Honneth traz elementos de outras autoras como Susan Okin, Deborah Rhode e Anne Phillips. Okin (1989) entende que a dimensão sociopolítica compreende bases nas quais os contextos de Justiça são significativos na construção das relações sociais que implicam a figura de um sujeito desrespeitado que se situa rebaixado na ordem social, o que implica rebaixamento em todas as outras esferas da vida, a exemplo da família e os papeis de gênero que constroem a relação público e privado. Rhode (1991) pondera que esses contextos reverberam no Direito em seu sentido estrito senso em termos de reivindicações e estatuto constitucional desigual. Já Phillips (2011) vê a cultura e ressignificação social como atingidas pelos contextos na hierarquização e violência contra grupos sociais.

A questão colocada fica mais complexa do que Fraser aponta: paridade de participação não se demonstra aplicável no esquema honnethiano de argumentação, já que existem elementos que não são capazes de se mensurar. Será o esquema de Fraser "racional-instrumental" como indica Habermas $(2018,2014)$ ? Acreditamos que suscitar um debate neste confronto dos autores é essencial em pesquisas futuras, assim como criar divergências quando o debate se demonstra pouco explorado na Teoria Crítica.

\section{CONSIDERAÇÕES FINAIS}

$\mathrm{Na}$ perspectiva do debate entre Nancy Fraser e Axel Honneth, vemos um embate à procura de ressignificação da Teoria Crítica. A disputa por entre esses autores no que se refere ao ideal normativo e compreensivo acerca das bases teóricas, observamos que ambos concordam em alguns elementos: a relação dialética histórica entre desigualdades, o sistema capitalista, o sofrimento e as determinações relacionadas. Contudo, os autores divergem sobre aspectos explicativos e causais dessas relações, notadamente, no que trata das bases macro ou microssociais, estruturais ou não.

Fraser pondera que não há uma perspectiva que possa ser "micro" no âmbito do reconhecimento e das disputas individuais ou grupais unicamente. Há de se considerar elementos socioeconômicos e político-institucionais relativos à redistribuição, ao status, ao posicionamento nos meios de produção, à relação trabalho produtivo e trabalho reprodutivo, assim como bases institucionais das relações contratuais como o casamento. É primordial considerar que para o sistema social importam as relações redistributivas e de reconhecimento, e que ambas precisam ser consideradas plenamente como estruturais e não subordinadas - já que a subordinação, para Honneth, é prejudicial à compreensão da totalidade da realidade. Contudo, ressaltamos que, no próprio livro, Nancy Fraser pondera que seu sistema de perspectiva dualista está em desenvolvimento para incorporar uma terceira dimensão, o sistema representativo. 
Já Axel Honneth segue a linha de raciocínio hegeliana, pautando-se no reconhecimento como categoria que não apenas incorpora, como entende Fraser, mas que organiza todo o sistema social, da redistribuição ao casamento, dos contratos aos indivíduos. O reconhecimento se torna categoria central a partir do sujeito enquanto devir e enquanto potência, mesmo que o autor não associe diretamente autores que situaram estes conceitos. Ou seja, um sujeito mais autônomo e compreensivo de si, diferentemente da visão de Fraser. Vemos aqui o sofrimento de indeterminação, na própria concepção de Honneth (2003), ou seja, o horizonte onde se colocam as perspectivas em que o não reconhecimento se transforma em medida que atentará diretamente na formação individual e social dos sujeitos e, sobretudo, coloca-os na perspectiva moral, ética e de Justiça.

Vemos que os dois autores divergem em pontos nodais, entretanto, se aproximam intensamente. A questão que os coloca em confronto não é a relação reconhecimento versus redistribuição, mas a construção de onde se parte a análise. Honneth parte de uma perspectiva micro, de processos de subjetivação construídos na ética e com base na ideia de vida "boa". O princípio é o da eticidade de indivíduos e suas reverberações nas relações sociais. Já Fraser, parte da perspectiva macro, de relações estruturais, com base na construção paulatina de sujeito de justiça. O princípio é a paridade de participação, que só pode ser confrontada a partir de uma concepção de vida anterior no contexto de uma Justiça global. São questões que, obviamente, postas argumentativas das formas como os autores subscrevem, parecem ser inconciliáveis, porém, o que vemos é, de fato, um avanço no debate, e não uma estagnação pela mera discordância entre autores.

Outro ponto inconciliável entre os autores é questão da "boa" vida e da concepção de "bem”. Se essa questão se dá em termos estruturais ou microssociais, e se são necessários previamente para se pensar a Justiça. Pensar a Justiça em termos macro demanda ter em mente uma concepção prévia, a fim de que se organize as dimensões sociais da estrutura, delimitando como ocorrem as desigualdades e hierarquias que erguem esta estrutura e derivam a ordem social e os aspectos de acesso às dimensões de Justiça. Pensar a Justiça em termos micro, por outro lado, aponta para não concepção prévia, por entender que a construção se dá nas relações sociais primárias e estão em pleno desenvolvimento, assim, as concepções se desenvolvem conforme a intersubjetividade das relações.

Nancy Fraser e Axel Honneth contribuem, nesse ponto, para o desenvolvimento da Teoria Crítica em seu ponto mais fundamental: desenvolver elementos que permitam a compreensão da realidade com perspectivas engajadas de mudança social. O primeiro aspecto é que partir de uma análise macro ou micro não pode significar sua redução a um destes pontos. Em Fraser, podemos 
ter a desconsideração dos elementos afetivos que organizam as dimensões de reconhecimento e que podem ser um entrave à paridade de participação, por ter um elemento moral que não possa ser absorvido como critério de Justiça. E aqui podemos ter uma lógica demais abrangente que seja incapaz de considerar diferentes sociedades nas disputas por Justiça, porque se toma as mesmas como relativamente próximas em condições morais que permitam ter critérios de paridade. No caso de Honneth podemos ter os elementos de ordem afetiva como reguladores sociais que orientam todo o processo de reconhecimento e que pode subsumir compreensões mais amplas do porquê existir não-reconhecimento: será que o amor responde ao não-reconhecimento? Todas as esferas da vida contêm o amor como reconhecimento? No caso das mazelas socioeconômicas, as relações afetivas dariam conta para situar o início destes processos?

\section{REFERÊNCIAS}

ALEXANDER, M. (2011). The new Jim Crow: Mass Incarceration in the Age of Colorblindness. Nova York: The New Press.

BENHABIB, S. (1992). Situating the self: gender, community and postmodernism in contemporary ethics. Cambridge, UK: Polity Press.

BUTLER, J. (1999). Gender Trouble: Feminism and the subversion of Identity Nova York: Routledge.

DAHL, R. (1989). Democracy and its critics. London: Yale University Press.

DAVIS, A. Y. (1983). Women, Race \& Class. Nova York: Randon House.

DWORKIN, R. (1985). A Matter of Principle. Cambridge (Mass.) and London: Harvard University Press.

FLEISCHACKER, S. (2006). Uma breve história da justiça distributiva. Tradução de Álvaro de Vita. São Paulo: Martins Fontes: 2006. (Coleção Justiça e Direito).

FORRESTER, K. (2019). In the shadow of Justice: postwar liberalism and the remarking of political philosophy. Princeton: Princeton University Press.

FORST, R. (2010). Contextos da Justiça. Tradução de Denílson Luís Werle. São Paulo: Boitempo.

FRASER, N. (2017). A New Form of Capitalism? A Reply to Boltanski and Esquerre, New Left Review, vol. 106, p. 57-65.

FRASER, N. (2016). Contradiction of capital and care New Left Review, vol. 100, p. 99-117.

FRASER, N. (2013). Fortunes of Feminism London: Verso.

FRASER, N. (2009). Scales of justice: reimagining political space in a globalizing world. United States: Columbia University Press.

FRASER, N., HONNETH, A. (2003). Redistribution or recognition? A political-philosophical exchange. London: Verso. 
FRASER, N. (1989). Unruly practices: power, discourse and gender in contemporary social theory. Minneapolis: University of Minneapoly Press.

HABERMAS, J. (2018). A inclusão do outro: estudos de teoria política. Tradução de Denílson Luís Werle. São Paulo: Edunesp.

HABERMAS, J. (2014). Mudança estrutural na esfera pública. Tradução de Denílson Luís Werle. 3. ed. São Paulo: Edunesp.

HÖFFE, O. (2006). Justiça política. Tradução de Enildo Stein. 3. ed. São Paulo: Martins Fontes. (Coleção Justiça e Direito).

HONNETH, A. (2003). Luta por reconbecimento: a gramática moral dos conflitos sociais. Tradução de Luiz Repa. São Paulo: Editora 34.

HONNETH, A. (2007). Sofrimento de indeterminação: uma reatualização da Filosofia do direito de Hegel. Tradução de Rurion Melo. São Paulo: Editora Singular, Esfera Pública.

LORDE, A. (2007). Sister Outsider: essays and speeches by Audre Lorde. New York: Crossing Press.

MARSHALL, T. H. (1967). Cidadania, classe social e status. 1. ed. Rio de Janeiro: Zahar Editores.

OKIN, S. M. (1989). Justice, Gender, and the Family. Nova York: Basic Books.

PHILLIPS, A. (2011). Gender and Culture. Oxford, Oxford: Polity.

RAWLS, J. (1999). The Law of Peoples: with 'The Idea of Public Reason revisited'. Cambridge, Mass.: Harvard University Press.

RAWLS, J. (1996). Political Liberalism. Nova York: Columbia University Press.

RAWLS, J. (1971). A Theory of Justice Cambridge, Massachusetts: Harvard University Press.

RHODE, D. (1991). Justice and Gender: Sex Discrimination and the Law. Cambridge: Harvard University Press.

YOUNG, I. M. (1990). Justice and the Politics of Difference Princeton: Princeton University Press.

YOUNG, I. M. (1997). Intersecting Voices: Dilemmas of Gender, Political Philosophy and Policy. Princeton: Princeton University Press.

YOUNG, I. M. (2011). Responsibility for Justice. Oxford: Oxford University Press. 